IIIIIIIIIIIIIIIIIIIIIIIIIIIIIIIIIIII

Original Article

IIIIIIIIIIIIIIIIIIIIIIIIIIIIIIIIII

\title{
Herbicide discharge from rice paddy fields by surface runoff and percolation flow: A case study in paddy fields in the Lake Biwa basin, Japan
}

\author{
Miki Sudo, ${ }^{1, *}$ Yuko Goto, ${ }^{2}$ Kenji Iwama ${ }^{1}$ and Yoshifumi Hida ${ }^{1}$ \\ ${ }^{1}$ School of Environmental Science, The University of Shiga Prefecture, 2500 hassaka, Hikone-shi, Shiga 522-8533, Japan \\ ${ }^{2}$ College of Life and Health Sciences, Chubu University, 1200 Matsumoto-cho, Kasugai, Aichi 487-8051, Japan
}

(Received September 14, 2017; Accepted November 26, 2017)

\begin{abstract}
The transport of three herbicides, pyriminobac-methyl, imazosulfuron and pyraclonil from a watershed that includes 40 ha of paddy fields to a drainage canal was monitored in the Lake Biwa basin, Japan. Based on the intensive monitoring of all paddy plots and in the drainage canal conducted on 3 days during and after the application period, the passage of herbicide discharge from the paddy fields to the drainage canal was separated into surface runoff obtained from field observations and percolation flow calculated from the herbicide mass balance. Surface runoff from paddy plots immediately after herbicide application, discharging a large volume of paddy water, or both processes in conjunction had a significant effect on herbicide discharge. Without surface runoff, paddy fields discharged a consistently high amount of herbicide gradually by percolation flow. These results suggest that considerable amounts of herbicides were discharged into the drainage canal through percolation even if appropriate water management to prevent herbicide surface runoff was practiced. @ Pesticide Science Society of Japan
\end{abstract}

Keywords: herbicide discharge, paddy fields, surface runoff, percolation flow.

\section{Introduction}

Pesticide usage on farmland contributes to high cultivation yields, high-quality products, and effective farm management. The total land devoted to rice paddies is estimated to be $50 \%$ of the agricultural land in Japan, ${ }^{1)}$ and various herbicides are widely used to control weeds in paddy fields. Meanwhile, public concern is growing over ecological risks and water pollution caused by pesticides discharged from paddy fields. In field-monitoring studies of rivers ${ }^{2-10)}$ and lakes, ${ }^{11-13)}$ pesticides commonly used in rice paddy plots during the cultivation period have been detected frequently. In addition to field observations, simulation models such as PADDY ${ }^{14-16)}$ (Pesticide Paddy Field Model) and PCPF-1 ${ }^{17-19)}$ (The Pesticide Concentration in a Paddy Field model) were developed in Japan to assess and manage the potential environmental risks associated with pesticide discharge from paddy fields.

One of the pesticide transport processes from paddy fields into drainage canals is surface runoff caused by excessive irrigation, heavy rainfall events, and intentional drainage by farmers. The other is percolation flow caused by deep percolation and lateral seepage through bunds. Previous reports ${ }^{5,20-23)}$ of field ob-

\footnotetext{
* To whom correspondence should be addressed.

E-mail: sudo@ses.usp.ac.jp

Published online January 31, 2018

(c) Pesticide Science Society of Japan
}

servations and model simulations ${ }^{15,19,22,24,25)}$ revealed that surface runoff, especially that which occurred a few days after pesticide application, is responsible for a significant amount of pesticide discharge from paddy fields because of the high concentrations of pesticides in paddy water. Based on this information, spillover water management has been recognized as an inappropriate farm practice. In addition, the water retention period, which is how long water is held within the paddies to prevent surface runoff, is now being paid significant attention in order to reduce pesticide discharge. ${ }^{24)}$

A number of studies have estimated pesticide discharge by surface runoff; however, studies using field observations and model simulations that focus on discharge by percolation are limited. Sudo et al. ${ }^{26)}$ reported that the cumulative loss of the herbicide pretilachlor due to lateral percolation flow from a single paddy plot ranged from 7.4 to $16.3 \%$ of the applied mass and the loss increased proportionally with the percolation flow rate. Inao et al. ${ }^{27)}$ reported an improved PADDY-Large model including lateral-seepage pesticide loss through bunds, which successfully simulated the temporal changes in pesticide concentrations in a river drainage system. However, no studies to date have evaluated herbicide discharge caused by percolation flow at the watershed scale in Japan. The objective of this study was to quantitatively assess paddy herbicide discharge by surface runoff and percolation flow from paddy fields. 


\section{Materials and Methods}

\section{Site description}

Field observations were conducted in a watershed located in the Lake Biwa basin in Shiga Prefecture, Japan (N35 $10^{\prime}$, E136 $\left.00^{\prime}\right)$. The climatic conditions in Shiga Prefecture are characterized by annual precipitation of about $1,600 \mathrm{~mm}$ and an average temperature of $15^{\circ} \mathrm{C}^{28)}$ The watershed is divided into an upper area of 38.0 ha consisting of forested and residential areas and a lower area of 40.5 ha consisting of paddy fields, farm roads, and a drainage canal. Paddy fields in this area are managed by private farmers or a village-based farming organization. The layout of the watershed and the locations of the observation sites and plots are shown in Fig. 1.

The paddy landscape in the watershed is classified as flat or gently sloped. The total number of paddy plots is 120 and the area of individual paddy plots ranges from 0.1 to 0.3 ha. Twothirds of the paddy fields are used for rice cultivation (rice fields) and one-third for wheat cultivation (wheat fields) under the policy of reducing rice acreage. Six sub-drainage canals drain water from the upper area and adjacent paddy plots. The lower area is grouped into six sub-blocks associated with drainage canals. The drainage water from sub-canals drains into the principal drainage canal and flows out to the drainage river.

The majority of the paddy plots are rectangular. A paddy plot is adjacent to its neighboring plot with long bunds (about $100 \mathrm{~m}$ ) made of concrete. One of the shorter sides (about $30 \mathrm{~m}$ ) is adjacent to the farm road and has an irrigation tap supply- ing irrigation water through a pipeline. The other side is a soil bund $150 \mathrm{~cm}$ wide, facing a sub-drainage canal. The height from the top of the bund to the paddy soil is about $20 \mathrm{~cm}$. The subdrainage canal is $50-100 \mathrm{~cm}$ wide and $100-150 \mathrm{~cm}$ deep, and the bottom $60 \mathrm{~cm}$ on both sides is made of concrete. Surface runoff from a paddy plot flows out gravitationally to the sub-drainage canal through a drainage pipe. The principal drainage canal is $270 \mathrm{~cm}$ wide and $150 \mathrm{~cm}$ deep.

In most of the rice fields, rice seedlings are transplanted between late April and early May, and flooding is maintained until late June. Wheat seed is sowed in October or November, and mature wheat is harvested in June. The soil in the agricultural fields is gray lowland soil with $1.16 \%$ organic carbon and a $\mathrm{pH}\left(\mathrm{H}_{2} \mathrm{O}\right)$ of 5.8.

\section{Water sampling and analysis}

To estimate the herbicide losses from the experimental watershed, the occurrence of surface runoff and the height of the paddy water level in individual paddy plots in the rice fields were monitored on May 18, May 25, and June 1, 2012. The daily rainfall amounts on these intensive monitoring dates were zero. ${ }^{28)}$ The paddy plots with transplanted rice seedlings equaled $97 \%$ of the total paddy fields on May 18 and $100 \%$ on May 25 and June 1.

On the intensive monitoring days, the distance between the top of the paddy water and the top of the drainage gate (Dwg) was measured for all paddy plots. A negative Dwg value means that the paddy water overflows as surface runoff. For the paddy

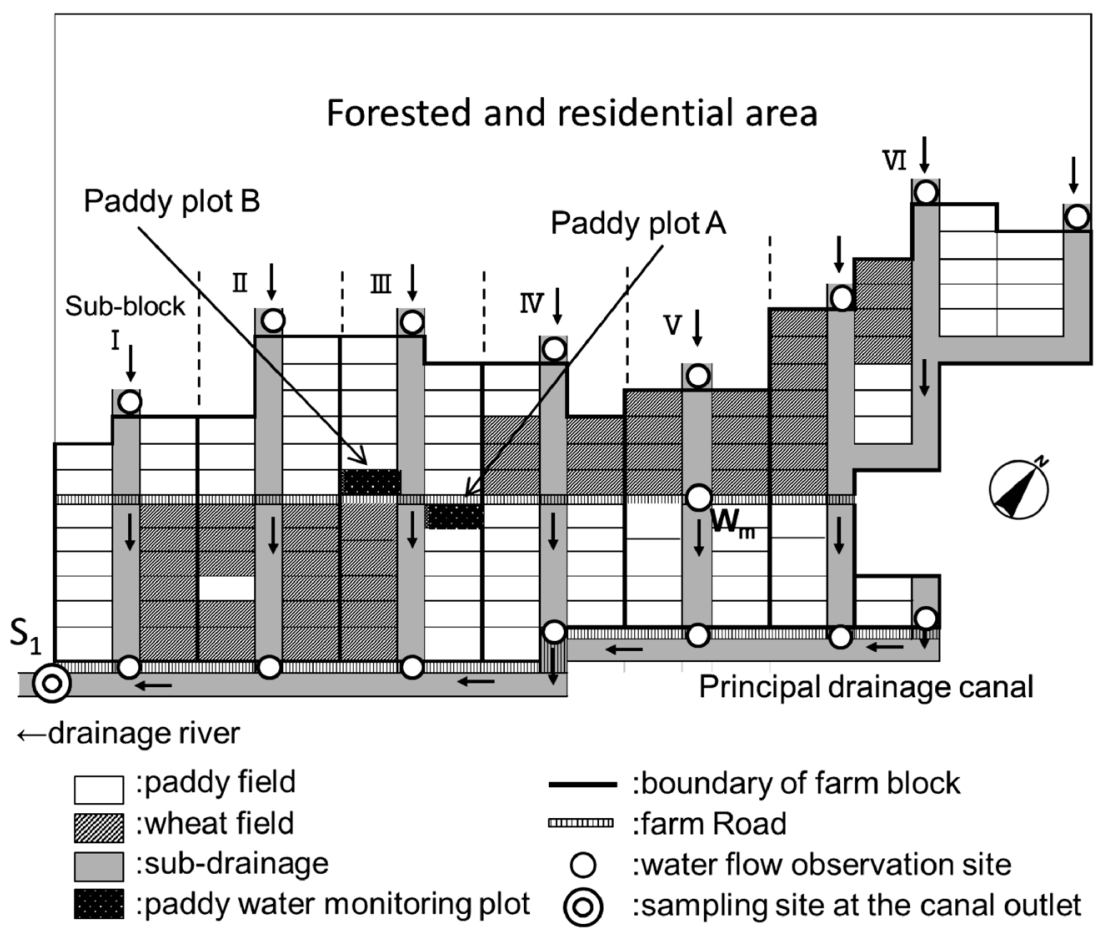

Fig. 1. Layout of the experimental watershed and location of the observation sites and plots. $\mathrm{S}_{1}$ : Sampling site at the canal outlet to monitor the water flow and herbicide concentration. Wm: Water flow observation site to evaluate the water flow from the wheat fields. 
plots where surface runoff was observed, runoff water was sampled directly from the drainpipe and the volume of water outflow was measured for the time needed to fill a 1 or $3 \mathrm{~L}$ container. Water samples collected from overflowing paddy plots were prepared as approximately $1 \mathrm{~L}$ of runoff-volume-weighted composite (composite water sample from surface runoff) for every sub-block. The flow rates of the sub-drains at the inlet and outlet and that of total drainage at the outlet of the principal drainage canal (Fig. 1, $\mathrm{S}_{1}$ ) were calculated from the cross-sectional area of the flow and flow velocity. To evaluate the water flow from the wheat fields, the water flow at $\mathrm{W}_{\mathrm{m}}$ (Fig. 1) was also monitored on May 25 and June 1.

To monitor the changes in herbicide concentrations in the paddy water, paddy water from paddy plots A and B (water sample from paddy water) was collected daily for 10 days following herbicide application and at 2- or 3-days intervals for the following 2 weeks. Drainage water samples at $S_{1}$ (water sample at $S_{1}$ ) were collected daily from May 1 to June 16 to analyze the herbicide concentrations from the rice fields. Information on the herbicides used, application rates, and application dates was collected by surveying the Japan Agricultural Cooperative's (JA's) records on agricultural products. No paddy-applied herbicides were used in the upper forested and residential areas.

\section{Analytical methods}

The herbicides studied were selected from a multitude of herbicides used in the rice fields: pyriminobac-methyl (methyl 2-(4,6-dimethoxy-2-pyrimixinyloxy)-6-[1-methoxyiminoethyl]benzoate), imazosulfuron (1-(2-chloroimidazo[1,2-a]pyridine3-ysulfonyl)-3-(4,6-dimethoxypyrimidin-2-y)), and pyraclonil (1-(3-chloro-4,5,6,7-tetrahydropyrazolo[1,5-a]pyridin-2-yl)-5(methyl-2-propyn-1-ylamino)-1H-pyrazole-4-carbonitrile). The selected herbicides are widely used in Japan, and the sum of domestic production and import mass in Japan in 2012 was $16 \mathrm{t}$ for pyriminobac-methyl, $92 \mathrm{t}$ for imazosulfuron, and $120 \mathrm{t}$ for pyraclonil. ${ }^{29)}$

Herbicides in the composite water samples from surface runoff, water samples from paddy water and water samples collected at $S_{1}$ were extracted using a solid-phase extraction cartridge, and the pesticide concentrations were quantified using a gas chromatograph with a mass spectrometer (GC-MS) for pyriminobac-methyl and a liquid chromatograph with a mass spectrometer (LC-MS) for imazosulfuron and pyraclonil. The details of the extraction method and GC-MS analytical method were reported previously. ${ }^{7)}$ LC-MS analyses were carried out on a Shimadzu HPLC System (LC10A-VP) equipped with a mass spectrometer (LC-2010A, Shimadzu Corp., Kyoto, Japan). The separation was performed using a $3 \mu \mathrm{m}$ reversed-phase C18 analytical column with a $100 \mathrm{~mm} \times 2.0 \mathrm{~mm}$ internal diameter (TSKgel Super-ODS, Tosoh, Tokyo, Japan). Deionized water containing $0.1 \%$ formic acid (mobile phase component A) and acetonitrile (mobile phase component B) was employed for the isocratic gradient program, which started with $10 \% \mathrm{~B}$ for $2.5 \mathrm{~min}$, changed from $10 \% \mathrm{~B}$ to $78 \% \mathrm{~B}$ in $1 \mathrm{~min}$ and then from $78 \% \mathrm{~B}$ to $100 \% \mathrm{~B}$ in $3 \mathrm{~min}$, and remained at $100 \% \mathrm{~B}$ for $6 \mathrm{~min}$. The injection volume was $10 \mu \mathrm{L}$, and the flow rate was $0.2 \mathrm{~mL} / \mathrm{min}$. The detection limit of the three herbicides was $0.06 \mu \mathrm{g} / \mathrm{L}$.

\section{Determination of the adsorption of the herbicides on soil} Determination of the adsorption of the herbicides on soil was conducted as reported previously. ${ }^{30)}$ Surface layer soil $(0-5 \mathrm{~cm})$ was collected from 20 paddy plots in the rice fields and mixed together as a lumped soil sample. The soil sample was air-dried and passed through a $2 \mathrm{~mm}$ sieve. The batch equilibrium technique was used to determine the soil adsorption constant of the herbicides. Into a $50 \mathrm{~mL}$ centrifuge glass tube, $4 \mathrm{~g}$ of soil sample and $10 \mathrm{~mL}$ of test solution containing $1.0 \mu \mathrm{g} / \mathrm{mL}$ of herbicides in $0.01 \mathrm{M}$ calcium chloride were added. The test tubes were shaken in the dark at $25^{\circ} \mathrm{C}$ for $3 \mathrm{hr}$, which was predefined as the time needed to reach equilibrium. The test tubes were centrifuged, and the supernatant solution was filtered and analyzed via GC-MS or LC-MS as described above. None of the three herbicides was detected from the supernatant prepared with herbicide-free $0.01 \mathrm{M}$ calcium chloride solution.

\section{Deep percolation in the paddy plots}

The deep percolation in paddy plots A and B was measured at 12 locations in each plot by decreasing the water levels in the PVC pipes ( $15 \mathrm{~cm}$ diameter, $40 \mathrm{~cm}$ length), which were installed into the soil at a depth of approximately $20 \mathrm{~cm}$ to reach the plough pan. The average of the deep percolation flow was estimated by subtracting evaporation from drawdown in the PVC pipes for $24 \mathrm{hr}$.

\section{Results}

\section{Herbicide application}

Three herbicides were studied from among the 15 herbicides listed in the pesticide application records of the experimental watershed. Pyriminobac-methyl consists of a mixture of its $(E)$-isomer and $(Z)$-isomer as active ingredients, with an $(E) /$ $(Z)$ ratio of $5: 1{ }^{31)}$ Photo-transformation of this compound is its major fate process in water, and $(E) /(Z)$ geometrical isomerization reached approximate equilibrium at $1: 1.35$ after $4.5 \mathrm{hr}$ of sunlight exposure. ${ }^{31)}$ The $(E)$ - and $(Z)$-isomers can be analyzed separately using a GC-MS; however, pyriminobac-methyl concentrations in this study are described as the sum of the $(E)$ - and (Z)-isomer.

In the experimental watershed, rice seedlings were transplanted between late April and mid-May. Herbicides were applied 4 to 7 days after rice transplantation in most of the paddy plots. Figure 2 shows the herbicide application amounts and application dates. The sums of the application amounts in the experimental watershed were $604 \mathrm{~g}$ for pyriminobac-methyl, $850 \mathrm{~g}$ for imazosulfuron, and $3,240 \mathrm{~g}$ for pyraclonil. The proportion of the total area of rice fields where commercial products containing each herbicide were applied was $30.6 \%$ of total rice fields for pyriminobac-methyl, $40.0 \%$ for imazosufuron, and $56.2 \%$ for pyraclonil. The concentrations at $S_{1}$ during May 1 and June 


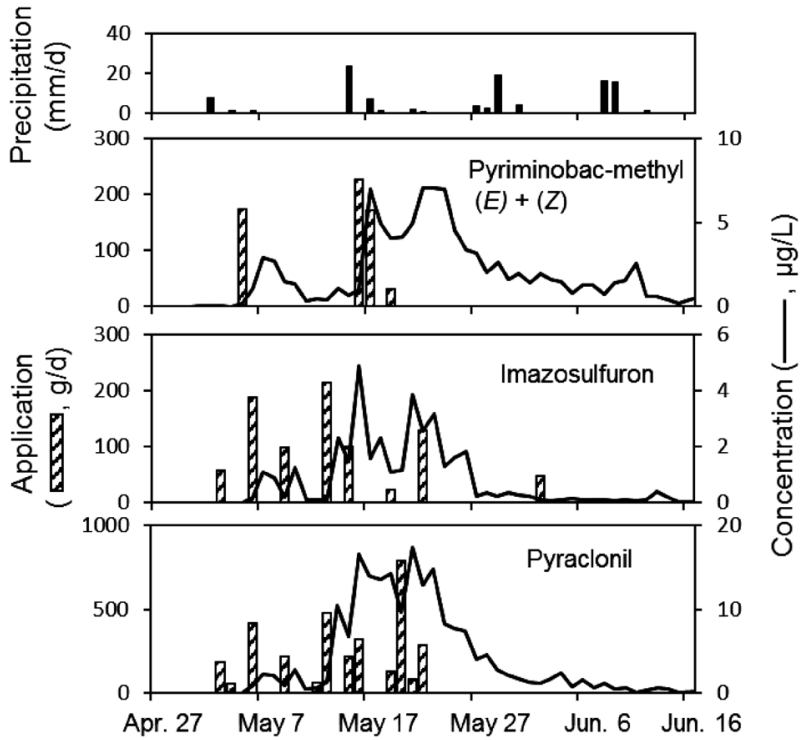

Fig. 2. Application amounts and application dates of herbicides in the rice fields and concentrations of herbicides at the canal outlet $\left(S_{1}\right)$.

16 are also shown in Fig. 2. In general, the concentrations increased in correspondence with the period of herbicide application and then gradually decreased. The peak concentrations were $7.1 \mu \mathrm{g} / \mathrm{L}$ for pyriminobac-methyl, $4.8 \mu \mathrm{g} / \mathrm{L}$ for imazosulfuron, and $17.4 \mu \mathrm{g} / \mathrm{L}$ for pyraclonil.

A commercial product containing pyriminobac-methyl was applied on May 5, 16, 17, and 19 in eight, six, six, and three paddy plots, respectively. The first intensive observation date (May 18) was within 2 days after two-thirds of the pyriminobacmethyl mass was applied. Imazosulfuron was applied as a single commercial product in 31 paddy plots from early May to midMay. Pyraclonil was an ingredient in three commercial products, one of which also contained imazosulfuron. Pyraclonil was applied in 42 paddy plots from early May to mid-May. The total herbicide masses applied up to the first observation date (May 18) were $75 \%$ of the imazosulfuron and $85 \%$ of the pyraclonil, with almost $100 \%$ of both herbicides applied by May 25 .

\section{Surface runoff and percolation flow from rice fields}

The Dwg distributions per number of paddy plots for the intensive observation dates are shown in Fig. 3. The arithmetic mean values of Dwg were $23 \mathrm{~mm}$ on May 18, $27 \mathrm{~mm}$ on May 25, and $30 \mathrm{~mm}$ on June 1, respectively. The number of paddy fields with a negative Dwg value, which indicates the occurrence of surface runoff, was 10 on May 18, nine on May 25, and nine on June 1 . Negative values of Dwg were mostly $>-10 \mathrm{~mm}$ except for the maximum Dwg value of $-32 \mathrm{~mm}$ on May 25. In the paddy plots with negative Dwg values, water management may have occurred simultaneously via irrigation and outflow. The water volume of surface runoff from the first and the second significant plots was, respectively, 0.43 and $0.14 \mathrm{~L} / \mathrm{s}$ on May 18 , 2.3 and $0.56 \mathrm{~L} / \mathrm{s}$ on May 25, and 0.49 and $0.30 \mathrm{~L} / \mathrm{s}$ on June 1 . In cases when the surface runoff continued throughout the day at

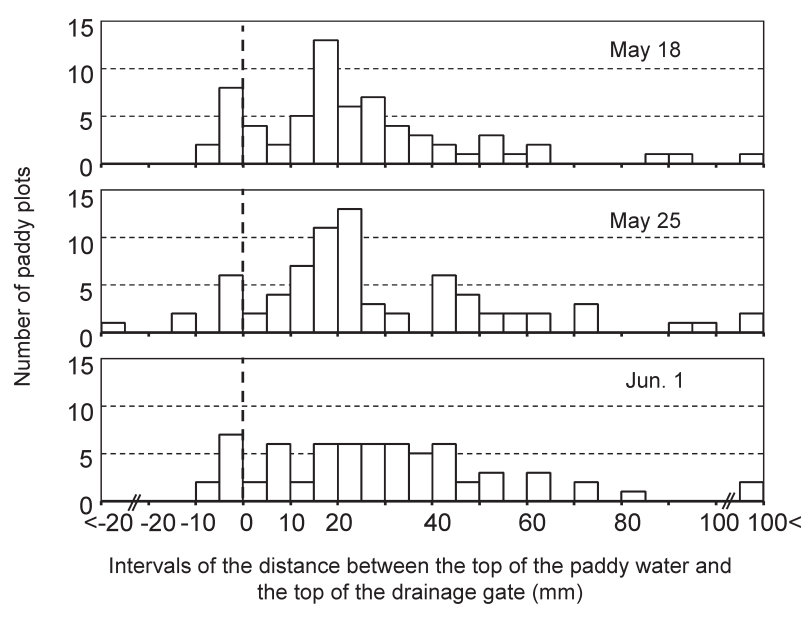

Fig. 3. Histograms of the distance between the top of the paddy water and the top of the drainage gate.

these rates, the corresponding values for each surface volume of the first and second significant plots were, respectively, 7.8 and $5.6 \mathrm{~mm}$ /day on May 18, 68.3 and $15.8 \mathrm{~mm}$ /day on May 25, and 13.7 and $10.5 \mathrm{~mm} /$ day on June 1 . The water balance in the paddy fields on the monitoring dates is described using Eq. (1), where $Q_{\text {outlet }}$ is the flow rate at $S_{1}$ and $Q_{\text {upper }}$ is the flow rate from the upper forested and residential areas, calculated from the sum of the flow rate at the sub-drainage inlets. $Q_{s}$ is the flow rate due to surface runoff from the rice fields, $Q_{p}$ is the percolation flow from the rice fields, and $Q_{W}$ is the flow rate from the wheat fields.

$$
\mathrm{Q}_{\text {outlet }}=\mathrm{Q}_{\text {upper }}+\mathrm{Q}_{\mathrm{s}}+\mathrm{Q}_{\mathrm{p}}+\mathrm{Q}_{\mathrm{w}}
$$

$Q_{s}$ was calculated using Eq. (2), where $Q_{s, i}$ is the sum of the flow rate by surface runoff from the paddy plots in sub-block $i$.

$$
\mathrm{Q}_{\mathrm{s}}=\Sigma \mathrm{Q}_{\mathrm{s}, i}
$$

As observations at $\mathrm{W}_{\mathrm{m}}$, on both May 25 and June 1 showed no increase in sub-drain flow rate through the wheat fields, the flow rate from the wheat fields was assumed to be negligible. The percolation flow from rice fields, $Q_{p}$, was calculated using the water balance in Eq. (1). Figure 4 shows the composition of the water flow on the intensive observation dates. Water flow from paddy plots accounted for $50-70 \%$ of that from watershed. Percolation

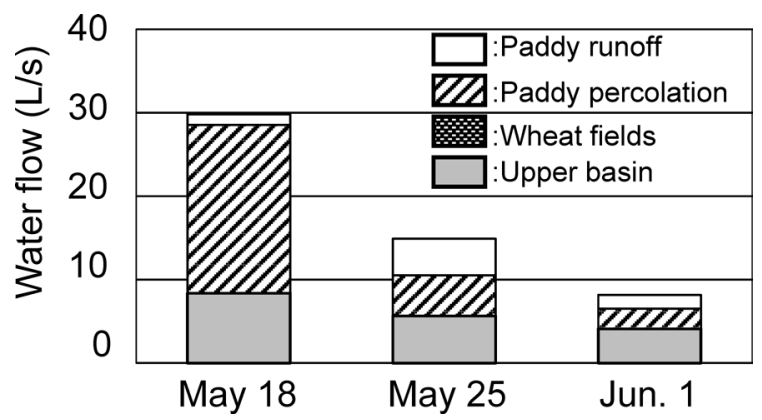

Fig. 4. Composition of the water flow from the experimental watershed. 


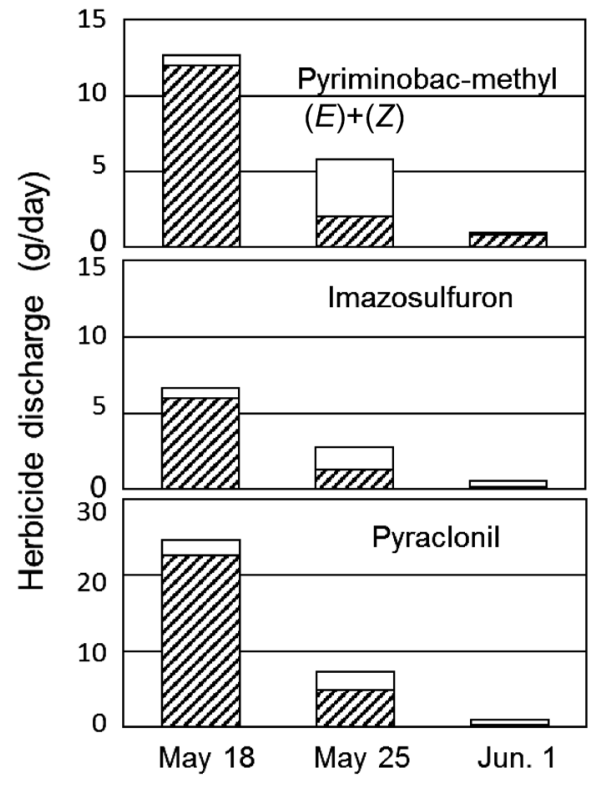

\section{:surface runoff $\mathbb{Z Z}$ :percolation flow}

Fig. 5. Composition of herbicide discharges.

flow from the paddy plots accounted for 94, 52, and 59\% of the total water flow from the paddy plots on May 18, May 25 and June 1 , respectively.

The mass balance of herbicides is described in Eq. (3), where $\mathrm{L}_{\text {outlet }}$ is the herbicide discharge at $\mathrm{S}_{1}, \mathrm{~L}_{\mathrm{s}}$ is the herbicide discharge by surface runoff, and $\mathrm{L}_{\mathrm{p}}$ is the herbicide discharge by percolation flow. The herbicide discharges at $\mathrm{S}_{1}\left(=\mathrm{L}_{\text {outlet }}\right)$ on May 18 , estimated as a percentage of the applied mass up to that day, were $2.2 \%$ for pyriminobac-methyl, $1.0 \%$ for imazosulfuron and $1.3 \%$ for pyraclonil.

$$
\mathrm{L}_{\text {outlet }}=\mathrm{L}_{\mathrm{s}}+\mathrm{L}_{\mathrm{p}}
$$

$\mathrm{L}_{\mathrm{s}}$ was calculated using Eq. (4), where $\mathrm{L}_{\mathrm{s}, i}$ is the sum of the herbicide discharge caused by surface runoff in sub-block $i$.

$$
\mathrm{L}_{\mathrm{s}}=\Sigma \mathrm{L}_{\mathrm{s}, i}
$$

$\mathrm{L}_{\mathrm{s}, i}$ was calculated using Eq. (5), where $\overline{\mathrm{C}}_{\mathrm{s}, i}$ is the herbicide concentration of the composite water sample from surface runoff in sub-block $i$.

$$
\mathrm{L}_{\mathrm{s}, i}=\mathrm{Q}_{\mathrm{s}, i} \times \overline{\mathrm{C}}_{\mathrm{s}, i}
$$

Both $\mathrm{L}_{\text {outlet }}$ and $\mathrm{L}_{\mathrm{s}}$ were obtained from observed data, and $\mathrm{L}_{\mathrm{p}}$ was calculated by the mass balance of the herbicide in Eq. (3). Figure 5 shows the composition of herbicides discharged from the rice fields. The herbicide discharge was highest on May 18 and decreased to $30-50 \%$ by May 25 and to less than $10 \%$ by June 1 . The herbicides discharged by percolation flow were estimated to be $90-95 \%$ of the total discharge on May 18, 35-65\% on May 25, and $25-85 \%$ on June 1 respectively.

\section{Herbicide concentration in the paddy water}

The commercial product containing pyriminobac-methyl was applied on paddy plot A on May 6, and another product containing imazosulfuron and pyraclonil was applied on paddy plot B on May 9. The herbicide concentrations in the paddy water are shown in Fig. 6. The concentrations in the paddy water were highest 1 day after application for pyriminobac-methyl and pyraclonil and 2 days after application for imazosulfuron. The maximum concentrations in the paddy water were $78 \mu \mathrm{g} / \mathrm{L}$ for pyriminobac-methyl, $110 \mu \mathrm{g} / \mathrm{L}$ for imazosulfuron, and $171 \mu \mathrm{g} / \mathrm{L}$ for pyraclonil. Following the peak concentrations, the concentrations decreased exponentially to less than $10-15 \%$ of the maximum 10 days after application and decreased gradually to less than $5 \%$ by the end of the sampling period.

Previous reports ${ }^{31-34)}$ showed that the elimination rate constant of herbicide concentrations in paddy water was assumed to follow biphasic first-order kinetics; an initial rapid-elimination phase followed by a second, slow-elimination phase. In the current study, the turning points between the two phases for herbicides were set to 10 days after application. The concentration in paddy water $\left(\mathrm{C}_{\text {paddy }}\right)$ at time $t$ during each phase was approximated by linear regression plotted against a semi-logarithmic scale and is expressed as Eq. (6).

$$
\mathrm{C}_{\text {paddy }}(t)=\mathrm{C}_{0} \times \exp (-\mathrm{k} t)
$$

where $\mathrm{C}_{0}$ and $\mathrm{k}$ are constants. The correlation coefficients of the estimated regression lines $\left(r^{2}\right)$ in the initial phase were 0.94 for

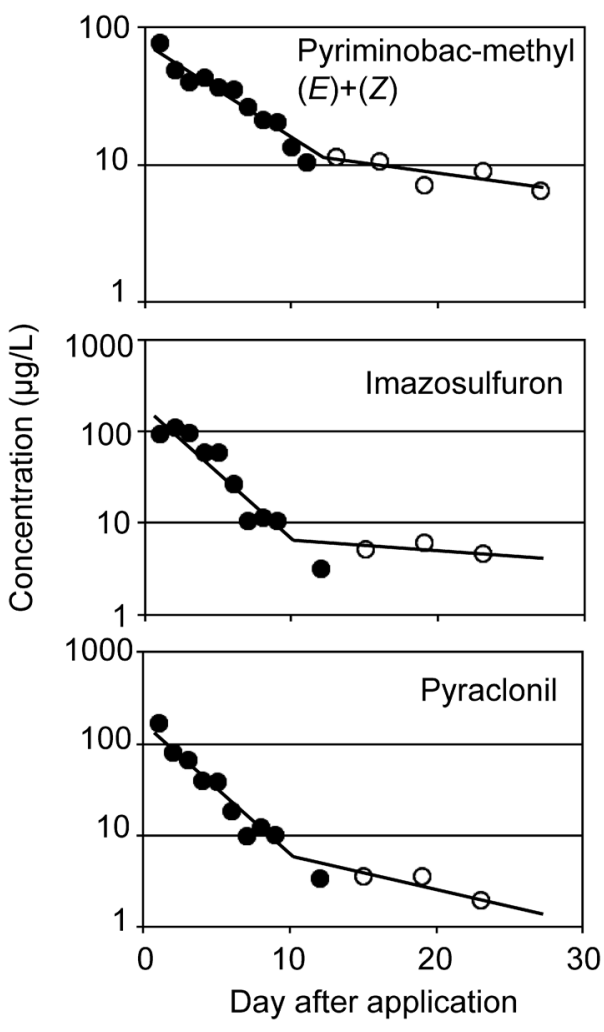

Fig. 6. Herbicide concentrations in paddy water. 
Table 1. Properties of herbicides

\begin{tabular}{|c|c|c|c|c|c|}
\hline & \multirow{2}{*}{ W.S. ${ }^{a)}(\mathrm{mg} / \mathrm{L})$} & \multirow{2}{*}{$K_{\mathrm{d}}$} & \multirow{2}{*}{$K_{\mathrm{oc}}$} & \multicolumn{2}{|c|}{ Half-life in paddy water ${ }^{b)}$} \\
\hline & & & & First phase (day) & Second phase (day) \\
\hline \multirow[t]{2}{*}{ Pyriminobac-methyl } & $9.3(E)^{30)}$ & 4.1 & 353 & 4.04 & 19.3 \\
\hline & $175(Z)^{30)}$ & & & & \\
\hline Imazosulfuron & $308^{33)}$ & 3.1 & 267 & 2.00 & 51.7 \\
\hline Pyraclonil & $50.1^{36)}$ & 3.2 & 276 & 2.02 & 9.3 \\
\hline
\end{tabular}

${ }^{a)}$ Water solubility. ${ }^{b}$ Half-life was calculated from lineare regression plotted against a semi-logarithmic scale. The turning points between the two phases was set to 10 days after application.

pyriminobac-methyl, 0.94 for imazosulfuron and 0.75 for pyraclonil. The elimination time to reach $50 \%$ of the initial concentration in the paddy water (half-life) calculated from the initial phase was 4 days for pyriminobac-methyl and 2 days for imazosulfuron and pyraclonil (Table 1). Takagi et al. ${ }^{34)}$ reported the half-life for imazosulfuron in paddy water as 3.1 days, which is in accordance with the value obtained in the present study.

\section{Adsorption of herbicides in soil}

The soil-water distribution coefficients $\left(K_{\mathrm{d}}\right)$ of the three herbicides are listed in Table 1 . The $K_{\mathrm{d}}$ values of the three herbicides ranged from 3.1 to 4.1 , and the $K_{\mathrm{oc}}$ values were 350 for pyriminobac-methyl, 270 for imazosulfuron and 280 for pyraclonil. A previous study reported that the $K_{\mathrm{d}}$ of imazosulfuron was 13.8. ${ }^{34)}$ The $K_{\mathrm{oc}}$ was reported as $220-1300^{35)}$ and $372-741^{31)}$ for pyriminobac-methyl, $160^{36)}$ and $754^{34)}$ for imazosulfuron, and $161-362^{37)}$ for pyraclonil, which is comparable to the values presented in the current study.

\section{Discussion}

\section{Dwg in the rice fields}

Excess water storage depth (EWSD) was defined by Phong et al. ${ }^{24)}$ as the storage capacity for excess rainfall and irrigation water. EWSD is the measured distance between the paddy water level and the top of the drainage gate; thus EWSD and Dwg are equivalent values. Kondo et al. reported ${ }^{23)}$ that the mean EWSD within 1 or 2 weeks after pesticide application on a non-rainy day was $8 \mathrm{~mm}$ for 264 plots surveyed in the Sakura River Basin in Ibaraki Prefecture and $3 \mathrm{~mm}$ for 154 plots in the Chikugo River Basin in Fukuoka Prefecture, where shallow paddy water management was recommended to prevent damage from pests. In a survey of the Sakura River Basin, $\mathrm{Vu}$ et al. ${ }^{8)}$ also reported that the mean value of EWSD for 296 paddy plots was $5 \mathrm{~mm}$ and 113 out of 296 surveyed plots had overflow drainage. There was a relatively high Dwg (=EWSD) of 23 to $30 \mathrm{~mm}$, and less than $15 \%$ of plots had surface runoff in the present study, which suggests that many farmers in the area may have purposefully not released large amounts of water containing pesticides and nutrients by using appropriate water management practices.

Good water management practices in this watershed are suggested; however, rainfall events can cause surface runoff from paddy plots. As shown in Fig. 2, the number of precipitation events observed from May 1 to June 16 in 2012 was 15, and the number of days with precipitation amounts of $<10 \mathrm{~mm} /$ day, $10 \mathrm{~mm} /$ day to $20 \mathrm{~mm} /$ day, $20 \mathrm{~mm} /$ day to $30 \mathrm{~mm} /$ day, and $>30 \mathrm{~mm}$ /day was $11,3,1$, and zero, respectively. For 5 years (2012 to 2016), the number of days with precipitation amounts of $<10 \mathrm{~mm} /$ day, $10 \mathrm{~mm} /$ day to $20 \mathrm{~mm} /$ day, $20 \mathrm{~mm} /$ day to $30 \mathrm{~mm} /$ day, and $>30 \mathrm{~mm} /$ day was $48,14,7$, and 2 , respectively, and the maximum precipitation amount was $35 \mathrm{~mm} /$ day in 2015. As precipitation events with more than $30 \mathrm{~mm} /$ day had low occurrence probability, the occurrence of surface runoff discharge was judged for all paddy plots by whether the assumed daily precipitation amount of less than $30 \mathrm{~mm} /$ day at $10 \mathrm{~mm} /$ day intervals $(10,20$, and $30 \mathrm{~mm} /$ day) exceeded the Dwg value on the monitoring day. On May 18, the number of paddy plots discharging surface runoff was estimated to be 16 for $10 \mathrm{~mm} /$ day precipitation (sum of the area accounted for $23 \%$ of the total rice field area), 34 for $20 \mathrm{~mm} /$ day (45\%), and 45 for $30 \mathrm{~mm} /$ day (60\%). The number of paddy plots was assumed to be $15(21 \%)$, $34(46 \%)$, and $49(63 \%)$ on May 25 for 10,20 , and $30 \mathrm{~mm} /$ day, respectively, and 17 (25\%), 24 (34\%), and 36 (49\%) on June 1. Half of the paddy area has the potential to discharge surface runoff after $20 \mathrm{~mm}$ /day precipitation, which suggests that a considerable amount of pesticides could be released by some rainfall events during herbicide application periods.

\section{Percolation flow from the rice fields}

The percolation flow is the sum of the lateral flow and deep percolation. The lateral flow is the horizontal movement of ponded water into the bunds followed by discharge to drainage. Deep percolation consists of water moving downward to the groundwater. The average of the deep percolation flow in paddy plots $\mathrm{A}$ and $\mathrm{B}$ was $0.2 \mathrm{~mm} /$ day on both May 25 and June 1 . The percolation flow from rice fields shown in Fig. 4 expressed in $\mathrm{mm} /$ day units was $8.4,2.0$, and 1.0 on May 18, May 25, and June 1, respectively. The deep percolation rates presented here are rough estimates; however, the low values suggest that the contribution of deep percolation to the total percolation flow may be small or negligible in the experimental paddy fields.

Many researchers have pointed out the importance of lateral flow into a bund in the movement of paddy water. ${ }^{38-42)}$ The bund along the drainage canal may be distinctly permeable by preferential flow due to a lower bulk density and enhanced macroporosity established through cracks or fractures caused by the shrinkage of clay particles, decaying plant root channels, and 
biological burrows. In addition, the water level difference between paddy water and the top of the drainage water promotes water movement from a paddy plot to a drainage canal. Ponding water depth is a determining factor influencing the preferential water movement in the bund. The depth of paddy water was not measured directly in this study, but the arithmetic mean of the Dwg value shows that the paddy water level was highest on May 18. In addition, the depth of ponded water in this region is kept relatively high for several days after transplantation to promote rooting. Then the water depth is kept shallow to increase the soil temperature and to promote tillering until mid-summer drainage in late June, so the depth of the paddy water on June 1 may be lower than that expected from the Dwg owing to the practice of lowering the drainage gate. Thus, the decrease in lateral water movement from May 18 to June 1 may be due to the lower depth of the paddy water.

3. Herbicide concentration and discharge from paddy plots by surface flow

Figure 7 shows the relationship of herbicide concentrations in the surface runoff water in sub-block $i$ between the field observations $\left(\overline{\mathrm{C}}_{\mathrm{s}, i}\right)$ and expected values $\left(\overline{\mathrm{C}}_{\mathrm{s}-\mathrm{cal}, i}\right)$ based on the concentration in the paddy water. The paddy water concentration in each plot was assumed to follow Eq. (6) and $\overline{\mathrm{C}}_{\mathrm{s-cal}, i}$ was calculated using Eq. (7),

$$
\overline{\mathrm{C}}_{\mathrm{s} \text {-cal }, i}=\Sigma\left(\mathrm{C}_{\text {paddy }}(t)_{, j, i} \times \mathrm{Q}_{\mathrm{s}, j, i}\right) / \Sigma \mathrm{Q}_{\mathrm{s}, j, i}
$$

where $\mathrm{C}_{\text {paddy }}(t)$ is the paddy water concentration in each plot calculated using Eq. (6) and the number of days after application, $\mathrm{Q}_{\mathrm{s}}$ is the measured surface runoff flow rate, and subscript $j$ is a plot in which the herbicides are applied in sub-block $i$ by the intensive observation date. The concentration in paddy water can fluctuate depending on dissipation mechanisms, such as adsorption to soil, biological degradation, photodegradation, outflow to the drainage canal, and dilution by irrigation water. Yet pyriminobac-methyl $\left(r^{2}=0.72\right)$ and pyraclonil $\left(r^{2}=0.97\right)$ closely agree with regard to their field measurements and calculated values, as shown in Fig. 7. Therefore, the $k$ value in Eq. (6) can represent the changes in paddy water concentration in all of the experimental paddy plots. The calculated values for imazosulfuron tended to be higher in a couple of paddy blocks, including paddy plot(s) in which imazosulfuron was applied 2 or 3 days prior. Excluding these data, the correlation coefficient was 0.68 . As mentioned before, the concentration of imazosulfuron in the paddy water reached its maximum 2 days after application (Fig. 6). This may be due to the slower dissolution rate of imazosulfuron. Thus, the differences in water temperature, water level, and application density among the paddy plots could have led to the concentration fluctuation within a few days of application.

As mentioned above, herbicide discharge by surface runoff from any paddy plot could be estimated using Eq. (6), considering the application date and flow rate of surface runoff. On May 25 , the most significant paddy plot discharge of pyriminobacmethyl was estimated to be $85 \%$ of the total surface discharge.

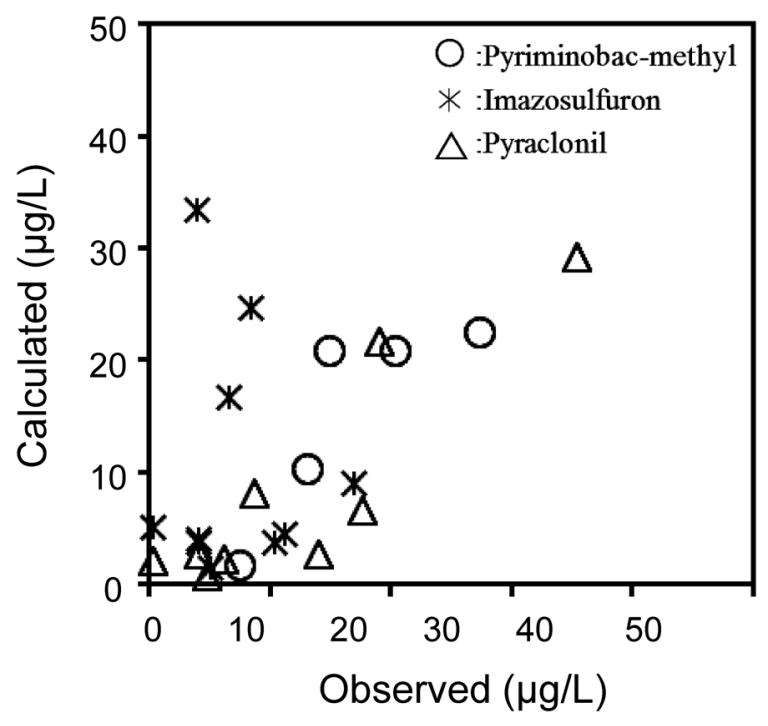

Fig. 7. Comparison of herbicide concentrations in surface runoff water in sub-block between observed and calculated values.

Pyriminobac-methyl was applied to the plot 8 days before the measurement and the concentration in the paddy water was relatively low; however, the surface flow was the highest $(2.3 \mathrm{~L} / \mathrm{s})$ among the experimental plots. On June 1, the most significant paddy plot for pyraclonil discharges was estimated to contribute $60 \%$ of the total surface runoff discharged from the rice fields. At this plot, the surface runoff flow rate was second highest $(0.11 \mathrm{~L} / \mathrm{s})$; however, the herbicide was applied 2 days prior, and the concentration in the paddy water was estimated to be high. Previous studies ${ }^{15,19,25)}$ show large pesticide losses result from spillover irrigation management. The current study indicates that surface runoff from even a single paddy plot with not only a large amount of water flow but also flow over an especially short duration after application has the potential to significantly affect pesticide discharge from the watershed.

4. Herbicide concentration in the percolation flow and distribution coefficient in the rice fields

Some field-plot scale simulations, e.g., PCPF-1 and PADDY, include the movement of water by lateral seepage out of the plot thorough bunds ${ }^{19,27)}$ however, the concentration in the percolation flow is not reported. The area-weighted average concentration in the percolation flow on an observation date $\left(\overline{\mathrm{C}}_{\mathrm{p}}\right)$ was estimated from the herbicide discharge at $\mathrm{S}_{1}\left(\mathrm{~L}_{\text {outlet }}\right)$ and discharge by surface runoff $\left(\mathrm{L}_{\mathrm{s}}\right)$ as follows:

$$
\overline{\mathrm{C}}_{\mathrm{p}}=\left(\mathrm{L}_{\text {outlet }}-\mathrm{L}_{\mathrm{s}}\right) / \mathrm{Q}_{\mathrm{p}} \times \Sigma \mathrm{A}_{j} / \mathrm{A}_{\mathrm{T}}
$$

where $A_{j}$ is the area of the paddy plot $j$ in which the herbicide was applied by the observation date and $A_{T}$ is the total area of the rice fields. Table 2 lists the average concentrations in the percolation water, as calculated using Eq. (8), on May 18, May 25, and June 1 . The concentrations observed at the outlet of the experimental watershed were around one-fifth or one-tenth of the $\overline{\mathrm{C}}_{\mathrm{p}}$ values (Fig. 2). The herbicide mass was diluted by the outflow 
Table 2. Calculated average concentrations in paddy water and in percolation water $(\mu \mathrm{g} / \mathrm{L})$

\begin{tabular}{|c|c|c|c|c|}
\hline & & May 18 & May 25 & Jun. 1 \\
\hline \multirow[t]{2}{*}{ Pyriminobac-methyl $(E+Z)$} & paddy water & 42.2 & 19.2 & 8.8 \\
\hline & percolation water & 25.1 & 15.9 & 13.1 \\
\hline \multirow[t]{2}{*}{ Imazosulfuron } & paddy water & 29.5 & 22.6 & 5.4 \\
\hline & percolation water & 10.6 & 7.7 & 1.9 \\
\hline \multirow[t]{2}{*}{ Pyraclonil } & paddy water & 38.0 & 20.5 & 3.3 \\
\hline & percolation water & 31.4 & 20.4 & 1.8 \\
\hline
\end{tabular}

of herbicide-free paddy plots and the inflow from the upper forested and residential areas.

The area-weighted average concentration in the paddy water on an observation date $\left(\overline{\mathrm{C}}_{\text {paddy }}\right)$ was also calculated, using Eq. (9).

$$
\overline{\mathrm{C}}_{\text {paddy }}=\Sigma\left(\mathrm{C}_{\text {paddy }}(t),{ }_{j} \times \mathrm{A}_{j}\right) / \Sigma \mathrm{A}_{j}
$$

where $\mathrm{C}_{\mathrm{paddy}, j}$ is the paddy water concentration calculated from Eq. (6) in paddy plot $j$ in which the herbicide was applied by the observation date. Table 2 presents the average concentrations in the paddy water calculated using Eq. (9) on May 18, May 25, and June 1 . Given that the bund soil porosity was saturated with soil water, the weight of soil and soil water in a unit was equal, and the concentration in the percolation water was the result of only the adsorption of paddy water to the bund soil (without an elimination effect such as degradation and evaporation), the apparent $K_{\mathrm{d}}$ value ( $\left.K_{\mathrm{d} \text {-field }}\right)$ was calculated using Eq. (10).

$$
K_{\text {d-field }}=\left(\overline{\mathrm{C}}_{\text {paddy }}-\overline{\mathrm{C}}_{\mathrm{p}}\right) / \overline{\mathrm{C}}_{\mathrm{p}}
$$

The $K_{\mathrm{d} \text {-field }}$ value on May 18 was 0.7 for pyriminobac-methyl, 1.8 for imazosulfuron, and 0.2 for pyraclonil. The higher value for imazosulfuron than for the other herbicides may have arisen from the uncertainty of the concentration calculated in the paddy water, as mentioned above. Comparing the $K_{\mathrm{d} \text {-field }}$ values with $K_{\mathrm{d}}$ values measured in the laboratory, the $K_{\mathrm{d} \text {-field }}$ values of the three herbicides were lower, as shown in Table 1 . The main reason for the difference between $K_{\mathrm{d} \text {-field }}$ and $K_{\mathrm{d}}$ may be the heterogeneousness in the adsorption process in the paddy field bunds. The $K_{\mathrm{d}}$ value is the ratio of herbicides in the aqueous phase and the adsorbed fraction in the solid phase at equilibrium. Meanwhile, the percolation flow consists of a variety of flows, ranging from the preferential water flow pathway, which funnels large volumes of water under the bund, to an almost matrix flow that moves very slowly. Slower movement may lead to a time lag and lower concentration due to the adsorption and degradation process in the bund soil. On the other hand, faster movement may prevent the herbicides from making contact with the soil or interacting with soils before they reach equilibrium and flow out to the drainage canal, thus keeping the concentration relatively high. The herbicide concentrations in the percolation water calculated in this study were the result of a mixture of percolation water outflow from various paddy plots in which herbicides were applied on different dates.

The $K_{\mathrm{d} \text {-field }}$ on May 25 decreased to 0.2 for pyriminobac-meth- $\mathrm{yl}$ and the concentrations of pyraclonil in paddy water and in percolation water were estimated to be almost the same. The decrease in the $K_{\mathrm{d} \text {-field }}$ value may be due to a steep decrease in concentrations in the paddy water, as the applications had been completed in almost all of the paddy plots (Fig. 6). In addition, percolation flow is heterogeneous and slower movement induces a time lag, as mentioned above. Slower movement may decrease the concentration in the percolation water; however, the concentration derived from percolation of the paddy water in the high-concentration period may have remained high in a drainage canal. Sudo et al. ${ }^{26)}$ also reported that the concentration of the herbicide pretilachlor in percolation water a week after application was observed to be higher than that in paddy water.

\section{Conclusion}

This study shows that paddy fields discharge considerable amounts of herbicides through percolation even if relatively appropriate water management is practiced. Thus, herbicides discharged through percolation need to be given more attention. The countermeasures by farmers against surface runoff to control herbicide discharge may be comparatively easier than those against percolation. One on-site solution to reduce underbund percolation may be to seal the bund walls with puddled soil material. Another potential solution is to maintain the depth of ponded water at an appropriately low level. At the watershed level, a cyclic irrigation system may play an important role in the reduction of pesticide discharge into rivers. ${ }^{8)}$ In any case, a detailed description of the bunds' water fluxes needs to be included in hydrologic modeling to predict pesticide fate and movement in a paddy plot. Based on precise percolation flow information, paddy field pesticides at the watershed scale from percolation may lead to assessments that are more realistic regarding pesticide discharges and a more effective countermeasure proposal.

\section{Acknowledgements}

The authors would like to thank Ms. Misaki Nishimura, Mr. Yasunori Oue, Ms. Saho Ikejiri and Ms. Mayu Ueno of the University of Shiga Prefecture for their assistance in field research and laboratory analyses. The authors also express sincere gratitude to the farmers in the experimental area for their generous help and close cooperation in this study. This research was supported by the Environment Research and Technology Development Fund (C-1102) of the Ministry of the Environment, Japan. 


\section{References}

1) Japan Statistics Bureau: "Japan Statistical Yearbook, 65th edition," Japan Static Association, Tokyo, 2015.

2) S. Maru: Ecol. Chem. 8, 3-10 (1985), (in Japanese).

3) T. Inoue, Y. Matsufuji, S. Hiraki and M. Aoki: J. Jpn Soc. Water Environ. 23, 438-443 (2000), (in Japanese).

4) A. Tanabe, H. Mitobe, K. Kawata, A. Yasuhara and T. Shibamoto: J. Agric. Food Chem. 49, 3847-3852 (2001).

5) S. Ebise and T. Inoue: Water Sci. Technol. 45, 127-131 (2002).

6) S. Ebise, K. Fukushima and N. Oike: J. JPN Soc. Water Environ. 26 , 699-706 (2003), (in Japanese).

7) M. Sudo, T. Okubo and R. Kaneki: Limnol 6, 91-99 (2005).

8) S. H. Vu, S. Ishihara and H. Watanabe: Pest Manag. Sci. 62, 11931206 (2006).

9) S. Ishihara, M. Ishizuka, T. Horio, Y. Kobara and M. Ueji: J. Weed Sci. Technol. 51, 69-81 (2006), (in Japanese).

10) T. Iwafume, K. Inao, T. Horio, N. Iwasaki, A. Yokoyama and T. Nagai: J. Pestic. Sci. 35, 114-123 (2010).

11) T. Inoue and S. Ebise: Res. Rep. Natl. Ins. Environ. Stud. Jpn. 144, 49-57 (1999), (in Japanese).

12) M. Sudo, T. Kawachi, Y. Hida and T. Kunimatsu: Limnol. 5, 77-86 (2004).

13) M. Sudo, M. Nishino and T. Okubo: Water Sci. Technol. 53, 131-138 (2006).

14) K. Inao and Y. Kitamura: Pest Manag. Sci. 55, 38-46 (1999).

15) K. Inao, Y. Ishii, Y. Kobara and Y. Kitamura: J. Pestic. Sci. 26, 229-235 (2001).

16) K. Inao, Y. Ishii, Y. Kobara and Y. Kitamura: J. Pestic. Sci. 28, 24-32 (2003).

17) H. Watanabe and K. Takagi: Environ. Technol. 21, 1379-1391 (2000).

18) H. Watanabe and K. Takagi: Environ. Technol. 21, 1393-1404 (2000).

19) H. Watanabe, K. Takagi and S. H. Vu: Pest Manag. Sci. 62, 20-29 (2006).

20) O. Nagafuchi, T. Inoue and S. Ebise: Jpn. Wat. Sci. Technol. 30, 137144 (1994), (in Japanese).

21) H. Watanabe, Y. Kakegawa and S. H. Vu: Paddy Water Environ. 4, 21-28 (2006)

22) H. Watanabe, M. H. T. Nguyen, K. Souphasay, S. H. Vu, T. K. Phong, J. Tournebize and S. Ishihara: Agric. Water Manage. 88, 132-140
(2007).

23) K. Kondo, J. Boulange, T. K. Phong, K. Hiramatsu, T. Inoue and H. Watanabe: J. Pestic. Sci. 37, 312-322 (2012).

24) T. K. Phong, H. Watanabe, Q. H. Thai, H. S. Vu, T. Tanaka, T. T. N. Dang and T. Motobayashi: J. Pestic. Sci. 33, 159-165 (2008).

25) T. K. Phong, K. Yoshino, K. Hiramatsu, M. Harada and T. Inoue: Paddy Water Environ. 8, 361-369 (2010).

26) M. Sudo, Y. Goto, T. Okajima, R. Horiuchi and H. Odani: J. Pestic. Sci. 37, 140-147 (2012).

27) K. Inao, N. Iwasaki, I. Kitayama and T. Horio: J. Pestic. Sci. 41, 59-63 (2016).

28) http://www.jma-net.go.jp/hikone/index.html/ (Accessed 22 Aug., 2017)

29) Japan Plant Protection Association: "Survey of pesticides," Japan Plant Protection Association, Tokyo, 2014.

30) E. Kawasaki, M. Sudo, T. Miki and F. Shibahara: J.JPN Soc. Water Environ. 31, 677-683 (2008), (in Japanese).

31) K. Inao, H. Mizutani, Y. Yogo and M. Ikeda: J. Pestic. Sci. 34, 273-282 (2009).

32) W. G. Johnson, T. L. Lavy and E. E. Gbur: J. Environ. Qual. 24, 493497 (1995).

33) F. Fajardo, K. Takagi, M. Ishizaka and K. Usui: J. Pestic. Sci. 25, 94100 (2000).

34) K. Takagi, F. F. Fajardo, M. Ishizaka, T. K. Phong, H. Watanabe and J. Boulange: Paddy Water Environ. 10, 139-151 (2012).

35) https://www.env.go.jp/water/sui-kaitei/kijun/rv/h29_pyriminobacmethyl.pdf (Accessed 31 Aug., 2017)

36) C. Tomlin (ed.): "The Pesticide Manual 15th edition," BCPC Publications, 2009.

37) https://www.env.go.jp/water/sui-kaitei/kijun/rv/h02_pyraclonil.pdf (Accessed 31 Aug., 2017).

38) M. Janssen and B. Lennarts: J. Hydrol. (Amst.) 369, 142-153 (2009).

39) H. C. Huang, C. W. Liu, S. K. Chen and J. S. Chen: J. Hydrol. (Amst.) 284, 13-25 (2003).

40) N. Tsubo, S. Fukai, T. P. Tuong and M. Ouk: Ecol. Modell. 204, 503515 (2007).

41) C. W. Liu, H. C. Huang, S. K. Chen and Y. M. Kuo: J. Am. Water Resour. Assoc. 40, 603-614 (2004).

42) X. Q. Liang, H. Li, Y. X. Chen, M. M. He, G. M. Tian and Z. J. Zhang: J. Environ. Qual. 37, 712-717 (2008). 